\title{
Pathogenic copy number variants and SCN1A mutations in patients with intellectual disability and childhood-onset epilepsy
}

Andrew E. Fry ${ }^{1,2^{*}}$, Elliott Rees ${ }^{3}$, Rose Thompson³ ${ }^{3}$ Kiran Mantripragada ${ }^{3}$, Penny Blake ${ }^{4}$, Glyn Jones ${ }^{5}$, Sian Morgan ${ }^{1}$, Sian Jose ${ }^{1}$, Hood Mugalaasi ${ }^{1}$, Hayley Archer ${ }^{1}$, Emma McCann ${ }^{6}$, Angus Clarke ${ }^{1,2}$, Clare Taylor $^{1}$, Sally Davies ${ }^{1}$, Frances Gibbon ${ }^{7}$, Johann Te Water Naude ${ }^{7}$, Louise Hartley ${ }^{7}$, Gareth Thomas ${ }^{8}$, Catharine White ${ }^{8}$, Jaya Natarajan ${ }^{9}$, Rhys H. Thomas ${ }^{10}$, Cheney Drew ${ }^{11}$, Seo-Kyung Chung ${ }^{11}$, Mark I. Rees ${ }^{11}$, Peter Holmans ${ }^{3}$, Michael J. Owen ${ }^{3}$, George Kirov ${ }^{3}$, Daniela T. Pilz ${ }^{1}$ and Michael P. Kerr ${ }^{3,5}$

\begin{abstract}
Background: Copy number variants (CNVs) have been linked to neurodevelopmental disorders such as intellectual disability (ID), autism, epilepsy and psychiatric disease. There are few studies of CNVs in patients with both ID and epilepsy.

Methods: We evaluated the range of rare CNVs found in 80 Welsh patients with ID or developmental delay (DD), and childhood-onset epilepsy. We performed molecular cytogenetic testing by single nucleotide polymorphism array or microarray-based comparative genome hybridisation.

Results: $8.8 \%(7 / 80)$ of the patients had at least one rare CNVs that was considered to be pathogenic or likely pathogenic. The CNVs involved known disease genes (EHMT1, MBD5 and SCN1A) and imbalances in genomic regions associated with neurodevelopmental disorders (16p11.2, 16p13.11 and 2q13). Prompted by the observation of two deletions disrupting SCN1A we undertook further testing of this gene in selected patients. This led to the identification of four pathogenic SCN1A mutations in our cohort.

Conclusions: We identified five rare de novo deletions and confirmed the clinical utility of array analysis in patients with ID/DD and childhood-onset epilepsy. This report adds to our clinical understanding of these rare genomic disorders and highlights SCN1A mutations as a cause of ID and epilepsy, which can easily be overlooked in adults.
\end{abstract}

Keywords: Array comparative genomic hybridization, Intellectual disability, Epilepsy, Copy number variation, SCN1A

\section{Background}

Copy number variants (CNVs; chromosomal deletions and duplications) have been identified as significant aetiological factors in a range of neurodevelopmental disorders including intellectual disability (ID) [1], autism [2], epilepsy [3] and psychiatric disease [4]. The detection of a causative $\mathrm{CNV}$ in a patient is valuable for genetic counselling and, in

\footnotetext{
* Correspondence: andrew.fry2@wales.nhs.uk

${ }^{1}$ Institute of Medial Genetics, University Hospital of Wales, Cardiff CF14 4XW, UK

${ }^{2}$ Institute of Cancer and Genetics, Cardiff University, Cardiff CF14 4XN, UK Full list of author information is available at the end of the article
}

some cases, guiding clinical management. The observation of a rare chromosomal abnormality in a patient with a rare neurological phenotype has occasionally been the vital clue leading to the identification of genes and pathways critical to brain development $[5,6]$. A limited number of previous genome-wide $\mathrm{CNV}$ studies have focused on patients with both epilepsy and ID [7-10]. We set out to investigate the rare CNVs present in a series of 80 patients with ID/developmental delay (DD) and childhood-onset epilepsy. Our aims were: to determine the frequency of pathogenic CNVs in the cohort; to define the clinical features of patients 
carrying pathogenic CNVs; to identify any sub-groups of patients particularly enriched for pathogenic CNVs; and to highlight candidate genes for epilepsy and ID/DD.

\section{Methods}

\section{Study subjects}

Participants were recruited between 2010 and 2014. Participants were 80 unrelated patients (49 adults and 31 children) identified through medical genetics, learning disability and paediatric neurology clinics around Wales (see Additional file 1: Table S1 for further demographic information). Participants lacked a molecular diagnosis and had not previously undergone high resolution genome-wide cytogenetic analysis $(<1 \mathrm{Mb}$ resolution). The majority of participants had previously been tested by karyotype $(61 / 80)$ combined with additional cytogenetic and molecular tests (Additional file 1: Table S2). Patients with known significant congenital brain malformations were excluded (e.g. malformations of cortical development, porencephaly, holoprosencephaly or intracerebral vascular malformations). $\mathrm{CNV}$ rates in the general population were estimated from 929 control subjects derived from the Wellcome Trust Case Control Consortium 2 National Blood Donors Cohort [11]. These were blood donors recruited by UK Blood Services and are therefore similar in ethnic origin to our mostly white British cohort. Controls were genotyped on Illumina OmniExpress single nucleotide polymorphism (SNP)-arrays.

\section{Ethics approval and consent to participate}

The study was approved by the Research Ethics Committee for Wales (09/MRE09/51). Informed consent for testing and publication was obtained from all participants (or their parents/legal guardians).

\section{Microarray analysis}

Genomic DNA was extracted from blood $(n=73)$ or saliva $(n=7)$. Samples were tested on one of three platforms: (i) Illumina610-Quad SNP-array $(n=20)$; (ii) Illumina OmniExpress SNP-array $(n=36)$; or (iii) microarray-based comparative genomic hybridization (array CGH) using a BlueGnome CytoChip ISCA $8 \times 60 \mathrm{k}$ v2.0 array $(n=24)$. Validation testing was performed by fluorescent in situ hybridisation, multiplex ligation-dependent probe amplification (MLPA) or by testing on a second array platform. The method for identifying CNVs depended on the array platform. SNP-array data was called using PennCNV [12]. Called CNVs were filtered by probe number (10 or more) and gene content (at least one). We excluded CNVs which had $50 \%$ or greater overlap with a CNV in the control cohort. However, for key genomic regions known to harbour recurrent $\mathrm{CNVs}$ associated with neurodevelopmental disorders which demonstrate incomplete penetrance $(1 \mathrm{q} 21.1,15 \mathrm{q} 11.2,15 \mathrm{q} 13.3,16 \mathrm{p} 11.2$ and 16p13.11) we allowed CNVs to be present at low frequency in controls $(<1 \%)$. Analysis focused on deletions and duplications larger than $100 \mathrm{~kb}$ and $250 \mathrm{~kb}$ respectively (50 kb for disease regions). Array CGH data was referenced against same sex control DNA (Promega) and analysed using Illumina BlueFuse Multi (v3.1) software, with data filtered on consecutive probes ( 3 or more) and size (as above). Imbalances detected by array CGH were interpreted by comparison with data from the Database of Genomic Variants, International Standards for Cytogenomic Arrays consortium and local laboratory data. Coordinates are based on hg19/GRCh37. Statistical comparisons were made using Fisher's exact test calculated with an online tool [13]. Parents and additional family members were analysed, where available, to determine if a CNV had arisen de novo or segregated with disease in a family. We assessed the clinical significance of CNVs based on their size, type, inheritance and whether they contained known disease genes. We were guided by the approach set out in previous publications $[7,14]$. Based on this assessment some CNVs were annotated as 'pathogenic' (e.g. a de novo deletion of a proven disease gene/region) or 'likely pathogenic' (e.g. large CNVs containing genes/regions previously linked to disease). Other CNVs were considered to be of unknown significance.

\section{SCN1A gene testing}

A subgroup of patients was tested for intragenic SCN1A mutations. Sequencing of the complete coding region and flanking sequence of the gene was performed by bidirectional Sanger sequencing $(n=4)$ or by targeted next-generation sequencing (NGS) $(n=11)$. Sequencing (Sanger or NGS) covered all the coding sequence of SCN1A along with 20 bp of flanking intron or untranslated region (UTRs). Sequencing did not cover the promoter, deep intronic regions or the rest of the UTRs. In silico analysis of detected variants included PhyloP [15], SIFT [16], Grantham distance [17], PolyPhen-2 [18] and CADD [19]. We also searched the Exome Aggregation Consortium (ExAC) database [20], dbSNP [21], ClinVar [22] and an SCN1A mutation-specific database [23]. Nucleotide and protein positions are based on NCBI Reference Sequences NM_001165963.1 and NP_001159435.1 respectively [24].

\section{Results and discussion}

The 80 patients had a range of epilepsy phenotypes including epileptic encephalopathy $(\mathrm{EE}, n=25)$, nonlesional focal epilepsies $(n=22)$, and genetic generalised epilepsy with ID (GGE-ID, $n=22$ ) (Table 1 ). In the remainder, the epilepsy phenotype was unclassified or 
Table 1 Epilepsy syndromes in the cohort at recruitment

\begin{tabular}{ll}
\hline Syndrome & Number \\
\hline Epileptic encephalopathy (EE) & 9 \\
Lennox-Gastaut syndrome & 3 \\
Dravet syndrome & 2 \\
West syndrome & 2 \\
Myoclonic astatic epilepsy & 2 \\
Epilepsy of infancy with migrating focal seizures & 1 \\
Ohtahara syndrome & 1 \\
Epilepsy with continuous spikes and waves during sleep & 5 \\
Unclassified EE with onset in infancy & \\
Genetic generalised epilepsy with intellectual disability (GGE-ID) & 3 \\
Myoclonic epilepsy & 1 \\
Progressive myoclonic epilepsy & 18 \\
Other GGE-IDs & 22 \\
Non-lesional focal epilepsies & 2 \\
Unclassified epilepsy & 9 \\
Unknown & 80 \\
Total &
\end{tabular}

unknown. We found $22.5 \%(18 / 80)$ of the cohort carried at least one rare CNV (Table 2). Three patients had more than one rare $\mathrm{CNV}$. The average size of the CNVs was $647 \mathrm{~kb}$ (median $488 \mathrm{~kb}$ ). We identified 8 CNVs considered to be likely $(n=3)$ or clearly pathogenic $(n=5)$ (Table 2). One patient (R660) had one clearly and one likely pathogenic CNV. This meant 7 $(8.8 \%)$ of our patients had pathogenic or likely pathogenic CNVs. Additional rare variants of uncertain clinical significance (VUS) were present in 11 further patients. We compared the frequency of CNVs in patients and controls. We found that large $(>500 \mathrm{~kb})$ low frequency $(<1 \%)$ genic CNVs were marginally more common in patients $(13 \%, 10 / 80)$ compared with controls $(11 \%, 105 / 929)$. However, this difference was not statistically significant $(P=0.71)$. The majority of patients had previously been tested by karyotype which will have depleted larger CNVs from the cohort.

\section{Pathogenic CNVs}

The five clearly pathogenic CNVs were all de novo deletions. We found a de novo $127 \mathrm{~kb}$ deletion of $2 \mathrm{q} 23.1$ in a woman with moderate ID, mildly dysmorphic facial features (long face, thin upper lip, slightly upslanting palpebral fissures, long nose) and seizures. The deletion disrupted the first two non-coding exons of the MBD5 gene. MBD5 encodes a member of the methyl-CpGbinding domain family. The MBD5 protein binds to methylated DNA and is thought to regulate gene expression by controlling chromatin modification [25]. Deletions of the $5^{\prime}$ - UTR of $M B D 5$ result in reduced expression of the gene [26]. Common clinical features in $M B D 5$ patients include ID/DD, seizures, language impairment, microcephaly, mild craniofacial dysmorphism and autism spectrum disorders (ASD) [26-28]. Interestingly, patients with CNVs confined to the 5'-UTR (like R911) have phenotypes similar to patients with larger 2q23.1 deletions. This highlights the critical impact of non-coding sequence at the locus [29].

We observed a de novo $182 \mathrm{~kb}$ deletion at 9q34.3 involving EHMT1 in an adult male (R660) with moderateto-severe ID, dysmorphic features (hypertelorism, mid face hypoplasia, prognathism), aggressive behaviour, autistic features, depression and epilepsy. Deletions at 9q34 involving EHMT1 are responsible for Kleefstra syndrome [30]. EHMT1 encodes a histone methyltransferase involved in transcriptional repression. EHMT1 is known to interact with MBD5 and they work together to regulate gene expression [25]. Characteristic features of Kleefstra syndrome include ID/DD, microcephaly, psychiatric disorders, severe behavioural problems, dysmorphic features, hypotonia, heart defects and seizures [31]. In addition to truncating EHMT1 the 9q34 deletion involved the adjacent $C A C N A 1 B$ gene. $C A C N A 1 B$ encodes a subunit of a voltage-dependent calcium channel expressed on neurons. Mutations in other N-type voltage-dependent calcium channel subunits have been linked to a wide range of paroxysmal disorders including periodic paralysis [32], familial hemiplegic migraine [33], myoclonus-dystonia syndrome [34], childhood absence epilepsy [35] and idiopathic generalized epilepsy [36]. Therefore, it is possible that haploinsufficiency of $C A C$ $N A 1 B$ may have contributed to the patient's epilepsy phenotype. Patient R660 also had a paternally-inherited $1.3 \mathrm{Mb}$ duplication involving the FHIT gene (considered to be likely pathogenic). The FHIT gene is a member of the histidine triad gene family. FHIT encodes diadenosine $5^{\prime}, 5^{\prime \prime \prime}$-P1,P3-triphosphate hydrolase, an enzyme involved in purine metabolism. Rare CNVs involving FHIT have previously been described in autism [37, 38]. R660 carried a third rare $\mathrm{CNV}$, a maternally-inherited $465 \mathrm{~kb}$ deletion at 3p22.1 involving ULK4. ULK4 encodes a serine/threonine kinase. Expression of the ULK4 gene is neuron-specific and developmentally regulated [39]. This third CNV was considered to be a VUS, although deletions in ULK4 have recently been reported as a potential risk factor for schizophrenia [39].

The third clearly pathogenic $\mathrm{CNV}$ was a de novo $603 \mathrm{~kb} 16 \mathrm{p} 11.2$ deletion in a girl with mild DD, ASD and infantile spasms (seizure free following treatment). Seizures are a common feature of $16 \mathrm{p} 11.2$ deletion syndrome along with ASD, ID/DD, psychiatric disease and increased risk of obesity $[40,41]$. The reciprocal duplications at $16 \mathrm{p} 11.2$ locus have also been associated with epilepsy including infantile spasms [7, 42]. The last two 
Table 2 Rare CNVs detected in 80 patients with ID/DD and epilepsy

\begin{tabular}{|c|c|c|c|c|c|c|c|c|c|c|c|c|c|c|}
\hline Subject & Age & Sex & Clinical features & $\begin{array}{l}\text { Seizure } \\
\text { onset }\end{array}$ & Syndrome & $\begin{array}{l}\text { Seizure } \\
\text { types }\end{array}$ & Cytoband & $\begin{array}{l}\text { CNV } \\
\text { Type }\end{array}$ & Coordinates & $\begin{array}{l}\text { Size } \\
(\mathrm{Kb})\end{array}$ & Tests & Status & Interpretation & Genes \\
\hline R125 & $10 \mathrm{~m}$ & $\mathrm{~F}$ & Severe DD, cleft palate & $3 \mathrm{~m}$ & EIMFS & $\begin{array}{l}\mathrm{FE}, \mathrm{EBCS}, \\
\mathrm{CSE}\end{array}$ & $2 q 24.3$ & Del & $\begin{array}{l}163823021- \\
167958723\end{array}$ & 4,136 & $c / f$ & DN & Path & $\begin{array}{l}\text { SCN3A, SCN2A, SCN1A, } \\
\text { SCN9A, SCN7A \& } 8 \text { others }\end{array}$ \\
\hline R351 & $15 y$ & M & $\begin{array}{l}\text { Moderate DD, poor } \\
\text { coordination, joint } \\
\text { contractures, mildly } \\
\text { dysmorphic }\end{array}$ & $3 \mathrm{~m}$ & Dravet & $\begin{array}{l}\text { FS, GTCS, } \\
\text { CSE, M }\end{array}$ & $2 q 24.3$ & Del & $\begin{array}{l}166842637- \\
166918932\end{array}$ & 76 & $c / d$ & DN & Path & SCN1A \\
\hline R404 & $7 y$ & $\mathrm{~F}$ & Mild DD, ASD & $8 \mathrm{~m}$ & West & $\underline{I S}, \mathrm{Abs}$ & $16 \mathrm{p} 11.2$ & Del & $\begin{array}{l}29595483- \\
30198151\end{array}$ & 603 & $b / e, f$ & DN & Path & $\begin{array}{l}\text { DOC2A, KIF22, MAPK3, } \\
\text { PRRT2, QPRT, SEZ6L2 \& } 24 \text { others }\end{array}$ \\
\hline \multirow[t]{3}{*}{ R660 } & \multirow[t]{3}{*}{$21 y$} & \multirow[t]{3}{*}{ M } & \multirow{3}{*}{$\begin{array}{l}\text { Mod-severe ID, } \\
\text { challenging behaviour, } \\
\text { ASD, depression, } \\
\text { dysmorphic }\end{array}$} & \multirow[t]{3}{*}{$8 \mathrm{~m}$} & \multirow[t]{3}{*}{ GGE-ID } & \multirow[t]{3}{*}{$\begin{array}{l}\text { Abs, M, } \\
\text { FDS, } \\
\text { EBCS }\end{array}$} & $9 q 34.3$ & Del & $\begin{array}{l}140707889- \\
140890373\end{array}$ & 182 & $b / e$ & DN & Path & CACNA1B, EHMT1 \\
\hline & & & & & & & $3 p 14.2$ & Dup & $\begin{array}{l}59736299- \\
61023355\end{array}$ & 1,287 & $b / e$ & Pat & Likely & FHIT \\
\hline & & & & & & & $3 p 22.1$ & Del & $\begin{array}{l}41359533- \\
41824555\end{array}$ & 465 & $b / e$ & Mat & VUS & ULK4 \\
\hline R911 & $22 y$ & $\mathrm{~F}$ & $\begin{array}{l}\text { Mod ID, small head, mildly } \\
\text { dysmorphic }\end{array}$ & $10 y$ & $\mathrm{FE}$ & FDS, GTCS & $2 q 22.3$ & Del & $\begin{array}{l}148691873- \\
148818437\end{array}$ & 127 & $b / e$ & DN & Path & $M B D 5, O R C 4$ \\
\hline R913 & $20 y$ & M & $\begin{array}{l}\text { Mod-severe ID, challenging } \\
\text { behaviour, ASD }\end{array}$ & $10 \mathrm{~m}$ & $\mathrm{FE}$ & $\begin{array}{l}\mathrm{FS}, \mathrm{FDS}, \\
\mathrm{EBCS}\end{array}$ & 16p13.11 & Dup & $\begin{array}{l}15512574- \\
16262571\end{array}$ & 750 & $b / e$ & Mat & Likely & $\begin{array}{l}\text { ABCC1, C16orf45, FOPNL, } \\
\text { KIAA0430, MIR484, MYH11, NDE1 }\end{array}$ \\
\hline R345 & $27 y$ & $\mathrm{~F}$ & Mild ID, dysmorphic & $<6 y$ & GGE-ID & $\begin{array}{l}\text { M, Abs, } \\
\text { GTCS }\end{array}$ & $2 q 13$ & Del & $\begin{array}{l}111392259- \\
113094793\end{array}$ & 1,703 & $\mathrm{~b} / \mathrm{e}$ & Pat & Likely & $\begin{array}{l}\text { BUB1, BCL2L11, ANAPC1, } \\
\text { MERTK, FBLN7 \& } 5 \text { others }\end{array}$ \\
\hline R58 & $26 y$ & $\mathrm{~F}$ & Severe ID, scoliosis & $<8 y$ & GGE-ID & At, Abs, M & $1 \mathrm{q} 21.1$ & Dup & $\begin{array}{l}145625979- \\
145723645\end{array}$ & 98 & $\mathrm{a} / \mathrm{e}$ & Mat & VUS & CD160, RNF115 \\
\hline $\mathrm{R} 74^{\mathrm{a}}$ & $51 y$ & $\mathrm{~F}$ & Mild-mod ID, depression & $3 \mathrm{~m}$ & $\mathrm{FE}$ & $\begin{array}{l}\mathrm{FS}, \mathrm{FE} \\
\mathrm{EBCS}\end{array}$ & $1 \mathrm{p} 21.1$ & Del & $\begin{array}{l}104167778- \\
104297867\end{array}$ & 130 & $\mathrm{a} / \mathrm{e}$ & U & VUS & AMY1A, AMY1B, AMY1C, AMY2A \\
\hline R101 & $32 y$ & M & ID, seizures & $<16 y$ & $U$ & $U$ & $11 q 22.3$ & Del & $\begin{array}{l}109173027- \\
109325299\end{array}$ & 152 & $b / e$ & Pat & VUS & C11orf87 \\
\hline R198 & $19 y$ & M & $\begin{array}{l}\text { Severe ID, ASD, mild right } \\
\text { hemiparesis }\end{array}$ & $7 \mathrm{~m}$ & LGS & $\begin{array}{l}\mathrm{FE}, \text { IS, Abs, } \\
\overline{\mathrm{NCS}}, \mathrm{GTCS}, \\
\text { At, FDS }\end{array}$ & Xq28 & Del & $\begin{array}{l}150589930- \\
150811921\end{array}$ & 222 & $\mathrm{c} / \mathrm{nd}$ & U & VUS & PASD1 \\
\hline R528 & $23 y$ & M & $\begin{array}{l}\text { Severe ID, challenging } \\
\text { behaviour, ASD, dysmorphic, } \\
\text { regression }\end{array}$ & $11 y$ & $\mathrm{FE}$ & $\mathrm{FE}, \mathrm{Abs}$ & $15 q 13.3$ & Dup & $\begin{array}{l}32019919- \\
32514341\end{array}$ & 494 & $b / e$ & $U$ & VUS & CHRNA7 \\
\hline \multirow[t]{2}{*}{ R605 } & \multirow[t]{2}{*}{$41 y$} & \multirow[t]{2}{*}{ M } & \multirow[t]{2}{*}{ ID, seizures } & \multirow[t]{2}{*}{$<16 y$} & \multirow[t]{2}{*}{ U } & \multirow[t]{2}{*}{ U } & $15 q 11.2$ & Dup & $\begin{array}{l}22383292- \\
23272733\end{array}$ & 889 & $\mathrm{~b} / \mathrm{e}$ & Pat & VUS & $\begin{array}{l}\text { CYFIP1, NIPA1, NIPA2, } \\
\text { TUBGCP5 \& } 8 \text { others }\end{array}$ \\
\hline & & & & & & & $8 p 23.1$ & Del & $\begin{array}{l}11713852- \\
12204679\end{array}$ & 491 & $b / e$ & Mat & VUS & $\begin{array}{l}\text { CTSB, FAM66D, FAM86B1, } \\
\text { USP17L2, ZNF705D \& } 6 \text { others }\end{array}$ \\
\hline $\mathrm{R}_{622^{\mathrm{a}}}$ & $28 y$ & $\mathrm{~F}$ & $\begin{array}{l}\text { Moderate ID, challenging } \\
\text { behaviour }\end{array}$ & $6 \mathrm{~m}$ & GGE-ID & $\frac{\mathrm{IS}}{\mathrm{M}}, \mathrm{GTCS}$ & $18 p 11.22$ & Dup & $\begin{array}{l}10042023- \\
10581304\end{array}$ & 539 & $b / e$ & Mat & VUS & $A P C D D 1, N A P G$ \\
\hline
\end{tabular}


Table 2 Rare CNVs detected in 80 patients with ID/DD and epilepsy (Continued)

\begin{tabular}{|c|c|c|c|c|c|c|c|c|c|c|c|c|c|c|}
\hline \multirow[t]{2}{*}{ R650 } & $21 y$ & $M$ & $\begin{array}{l}\text { Mild ID, thin habitus, } \\
\text { depression }\end{array}$ & $18 \mathrm{~m}$ & GGE-ID & $\begin{array}{l}\text { Abs, M, } \\
\text { GTCS }\end{array}$ & $15 q 13.3$ & Dup & $\begin{array}{l}32029693- \\
32514926\end{array}$ & 485 & $\mathrm{a} / \mathrm{nd}$ & U & VUS & CHRNA7 \\
\hline & & & & & & & $15 q^{14}$ & Del & $\begin{array}{l}34700297- \\
34807869\end{array}$ & 108 & $\mathrm{a} / \mathrm{nd}$ & U & VUS & GOLGABA \\
\hline R786 & $9 y$ & M & $\begin{array}{l}\text { Moderate DD, Leg } \\
\text { hypertonia, dystonia }\end{array}$ & $2 y$ & $\begin{array}{l}\text { GGE-ID } \\
(M)\end{array}$ & $\mathrm{M}, \mathrm{Abs}, \mathrm{At}$ & $21 \mathrm{q} 21.3$ & Del & $\begin{array}{l}27715263- \\
27955385\end{array}$ & 240 & $\mathrm{a} / \mathrm{e}$ & Mat & VUS & CYYR1 \\
\hline R931 & $15 y$ & F & $\begin{array}{l}\text { Severe DD, ASD, } \\
\text { dysmorphic, microcephaly }\end{array}$ & $12 y$ & GGE-ID & $\underline{\text { GTCS }}$ & $7 q 11.22$ & Del & $\begin{array}{l}71815170- \\
72305671\end{array}$ & 491 & $b / e$ & Pat & VUS & $\begin{array}{l}\text { CALN1, MIR4650-1, } \\
\text { MIR4650-2, SBDSPI, TYWIB }\end{array}$ \\
\hline R981 & $5 y$ & $\mathrm{~F}$ & $\begin{array}{l}\text { Severe } \mathrm{DD} \text {, regression, } \\
\text { ASD, leg hypertonia }\end{array}$ & $1 w$ & GGE-ID & $\begin{array}{l}\text { Abs, At, } \\
M, T\end{array}$ & $3 p 26.3$ & Dup & $\begin{array}{l}726675- \\
1301830\end{array}$ & 575 & $\mathrm{c} / \mathrm{nd}$ & U & VUS & CNTNG \\
\hline
\end{tabular}

Age (at recruitment) and seizure onset in y(ears), $\mathrm{m}$ (onths) or w(eeks). Clinical features: ID intellectual disability, DD, developmental delay, ASD autism spectrum disorder

Age (at recruitment) and seizure onset in ylears), m(onths) or w(eeks). Clinical features. ID intellectual disability, DD, developmental delay, ASD autism spectrum disorder ID, LGS Lennox-Gastaut syndrome, $U$ unknown, West West syndrome Seizure types: Abs absence, At atonic, CSE convulsive status epilepticus, EBCS evolution to bilateral or convulsive seizures, FDS focal dyscognitive seizures, FS febrile seizures, GTCS generalised tonic-clonic seizures, IS infantile spasms, $M$ myoclonic, NCS non-convulsive status epilepticus, $T$ tonic, seizure type at presentation is underlined (when known)

CNV type, Dup(lication) or Del(eletion). Coordinates, chromosome position of first/last abnormal probes based on hg19/GRCh37. Tests, primary array/confirmation method: (a) Illumina610-Quad SNP-array, (b) Illumina

OmniExpress SNP-array, (c) BlueGnome CytoChip array CGH, (d) quantitative PCR, (e) Illumina Exome BeadChip or custom Illumina SNP array, (f) fluorescence in situ hybridization, and (nd) not done. Status: DN, de novo;

inherited Pat(ernally); Mat(ernally) or U(nknown). Interpretation (of clinical significance): Path(ogenic); Likely, likely pathogenic; VUS, variant of uncertain significance

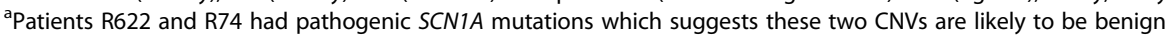


Table 3 SCN1A mutations in the cohort

\begin{tabular}{|c|c|c|c|c|}
\hline Subject & R622 & R74 & R710 & R769 \\
\hline Age & $28 y$ & $51 y$ & $24 y$ & $3 y$ \\
\hline Sex & $\mathrm{F}$ & $\mathrm{F}$ & $\mathrm{F}$ & $\mathrm{F}$ \\
\hline Clinical features & $\begin{array}{l}\text { Moderate ID, } \\
\text { challenging behaviour }\end{array}$ & $\begin{array}{l}\text { Mild-mod ID, } \\
\text { depression }\end{array}$ & $\begin{array}{l}\text { Moderate ID, ataxia, } \\
\text { stroke-like episodes }\end{array}$ & $\begin{array}{l}\text { Mod-severe DD, } \\
\text { poor coordination }\end{array}$ \\
\hline Seizure onset & $6 \mathrm{~m}$ & $3 \mathrm{~m}$ & $6 \mathrm{~m}$ & $5 d$ \\
\hline Syndrome & GGE-ID & FE & PME & CSWS \\
\hline Seizure types & IS, GTCS, M & $F S, F E, E B C S$ & C-CSE, M, FDS, EBCS & $\begin{array}{l}\text { T, GTCS, CSE, FE, } \\
\text { At, Abs, M }\end{array}$ \\
\hline Genomic coordinates & Chr2 g.166915177_166915180dup & Chr2 g.166915162 G > A & Chr2 g.166913001 G > C & Chr2 g.166848780 C > T \\
\hline CDNA & c.283_286dup & c.301C > T & c.393C > G & c.5005G > A \\
\hline Protein & p.Gly96Glufs*24 & p.Arg101Trp & p.Ser131Arg & p.Ala1669Thr \\
\hline Inheritance & De novo & De novo & $\begin{array}{l}\text { Segregates with } \\
\text { phenotype }\end{array}$ & De novo \\
\hline PhyloP & - & 0.91 (highly conserved) & 0.89 (highly conserved) & 0.86 (highly conserved) \\
\hline Grantham distance & - & 101 (moderate) & 110 (moderate) & 58 (small) \\
\hline SIFT & - & 0 (deleterious) & 0.02 (deleterious) & 0 (deleterious) \\
\hline $\begin{array}{l}\text { PolyPhen-2 } \\
\text { (HumVar) }\end{array}$ & - & 0.982 (probably damaging) & 0.368 (benign) & 1 (probably damaging) \\
\hline $\begin{array}{l}\text { CADD } \\
\text { (PHRED-scaled) }\end{array}$ & - & 34 (top $0.1 \%$ ) & 22.3 (top $1 \%$ ) & 26.1 (top $1 \%$ ) \\
\hline ExAC frequency & 0 & 0 & 0 & 0 \\
\hline dbSNP & - & rs121917965 & - & - \\
\hline
\end{tabular}

Age (at recruitment) and seizure onset in y(ears), m(onths) or d(ays). Clinical features: ID intellectual disability, $D D$ developmental delay Syndrome, electroclinical syndrome or main epilepsy type at recruitment: CSWS, epilepsy with continuous spikes and waves during sleep; FE focal epilepsy, GGE-ID genetic generalised epilepsy with ID, PME progressive myoclonic epilepsy

Seizure types: Abs absence, At atonic, C clonic, CSE convulsive status epilepticus, EBCS evolution to bilateral or convulsive seizures, FDS focal dyscognitive seizures, FS febrile seizures, GTCS generalised tonic-clonic seizures, IS infantile spasms, $M$ myoclonic, $T$ tonic, seizure type at presentation is underlined. Coordinates are based on hg19/GRCh37. Nucleotide and protein reference sequences were NM_001165963.1 and NP_001159435.1

clearly pathogenic CNVs were both de novo deletions at 2q24.3: one was $76 \mathrm{~kb}$ in size and deleted exons 4 to 28 of the SCN1A gene; the other was $4.1 \mathrm{Mb}$ and deleted 13 genes including SCN1A. SCN1A encodes a voltagegated sodium channel which is essential for the generation and propagation of action potentials in neurons. Mutations in SCN1A cause a spectrum of seizure disorders including familial febrile seizures, generalised epilepsy with febrile seizures plus and Dravet syndrome (severe myoclonic seizures of infancy) [43-45]. Typical features of these disorders are seizure onset in infancy with fever sensitivity. Severe manifestations of SCN1Arelated disease include pharmacoresistant seizures, ID/ DD, ataxia and autistic behaviour [46, 47]. Patient R125, who had the larger of the two deletions, had a severe phenotype with poor seizure control, severe DD and a cleft palate. These additional features may be due to haploinsufficiency of other genes in the region. The deletion in R125 included SCN2A, SCN3A and SCN9A. All three of these genes encode voltage-gated sodium channels which have been linked to epilepsy [48-50]. The patient's epilepsy phenotype was considered to be epilepsy of infancy with migrating focal seizures (EIMFS). A number of patients with 2q24.3 deletions and EIMFS -like phenotypes have recently been reported [51, 52]. Patient R351, who had the smaller of the 2q24.3 deletions, had previously undergone $S C N 1 A$ sequencing which had not detected their multi-exon deletion. This highlights that DNA sequencing alone is insensitive to $\mathrm{CNVs}$ and that dose-sensitive techniques (e.g. array $\mathrm{CGH}$ or MLPA) are required to detect a significant proportion of SCN1A mutations [53].

Two further likely pathogenic CNVs were found. One was a paternally-inherited $1.7 \mathrm{Mb}$ deletion of $2 \mathrm{q} 13$ in a female patient (R345) with mild ID, small ventricular septal defect, facial dysmorphism (long face, retrognathism, broad nasal root, hypertelorism, mild facial asymmetry) and epilepsy. Deletions at $2 \mathrm{q} 13$, similar to the one found in patient R345 have been reported in other patients with DD/ID $[54,55]$. Common manifestations include facial dysmorphism, autistic features, seizures and cardiac malformations. Previously reported 2q13 deletions have been inherited from an apparently normal parent, consistent with incomplete penetrance. Interestingly, the father of R345 shares similar facial features, but has no history of ID or epilepsy. The third likely 
pathogenic CNV was a maternally-inherited $750 \mathrm{~kb}$ duplication of 16p13.11 in a man with mild ID, ASD, seizures and a history of aggressive episodes. We considered the $16 \mathrm{p} 13.11$ duplication to be likely contributory as there was a family history of childhood epilepsy in the patient's mother and a maternal uncle (untested). Deletions in the $16 \mathrm{p} 13.11$ region are clear risk factors for neurodevelopmental disorders including epilepsy $[3,56]$. There is also evidence that duplications at $16 \mathrm{p} 13.11$ predispose to neurodevelopmental disorders (ASD, schizophrenia and ID) [57-60] and have been reported in patients with epilepsy [61]. Several further CNVs at genomic 'hot spots' were observed (duplications at 1q21.1, 15q11.2 and 15q13.3). These duplications were all inherited from unaffected parents and overlapped CNVs in the control cohort. They were therefore considered to be VUS. It remains possible that some of these VUS have contributed to disease risk. For example, there is evidence that CHRNA7 duplications may subtly increase the risk of neurodevelopmental disorders including ID [62]. However, further large-scale epidemiological studies are required to fully define these risks. Among the non-'hotspot' CNVs of uncertain significance we found a $575 \mathrm{~kb}$ duplication involving the first 4 exons of CNTN6. This duplication was identified in a 5-year-old girl with severe DD, ASD, bilateral lower limb hypertonia and early-onset seizures. CNTN6 is an interesting candidate gene for neurodevelopmental disorders as it encodes a neural adhesion molecule that operates in the formation, maintenance and plasticity of neuronal networks. In addition, CNVs involving CNTN6 have been reported in patients with DD/ID and autistic features [2, 63-65].

\section{SCN1A mutations}

Struck by finding two deletions involving SCN1A we realised that this key monogenic cause of epilepsy had not been extensively pre-screened in our cohort (only 9/80). The majority of recruits were adults $(n=49)$ who were initially investigated before $S C N 1 A$ testing was available. Furthermore, in contrast to paediatric settings, the significance of SCN1A mutations for adult patients is often neglected [66], usually because key elements of early history (e.g. age of onset, initial seizure types) are not available. We therefore selected a group of patients with early-onset epilepsy for SCN1A sequencing. Of the 38 patients with seizure onset before 12 months, 6 had previously had normal testing for SCN1A while 3 others had pathogenic CNVs. Fifteen of the remaining 29 patients were prioritized for testing based on clinical features (e.g. a history of myoclonic or febrile seizures). This found 4 pathogenic SCN1A mutations (Table 3). All four patients had seizure onset in early infancy (6 months or before) and ongoing seizures despite anticonvulsant therapy. Three of the mutations were missense mutations. The fourth was a 4 base duplication leading to a frameshift early in the gene. In silico analysis indicated the missense mutations were all deleterious changes affecting conserved residues (Table 3). One missense mutation segregated with epilepsy and ID phenotypes in the patient's family (the proband's two affected siblings and their mildly-affected mother) the others were all de novo. In combination with the array data these results indicate that at least $6 / 80(7 \%)$ of our cohort had SCN1A-related seizure disorders.

\section{Conclusions}

We have reported the range of rare CNVs found in a series of 80 Welsh patients with childhood-onset epilepsy and ID/DD. We identified clearly or likely pathogenic CNVs in 7 (8.8\%) of the patients including 5 rare de novo deletions. Our results highlight key genes for brain development including drawing attention to SCN1A mutations in adults with early-onset pharmacoresistant epilepsy and ID. Our results contribute additional phenotypic descriptions for these rare genomic disorders and support the use of molecular cytogenetic analysis in the genetic evaluation of patients with ID/DD and epilepsy.

\section{Additional file}

Additional file 1: Table S1. A detailed demographic description of the cohort. Table S2. Previous cytogenetic and molecular testing in the cohort. (DOCX $17 \mathrm{~kb})$

\section{Abbreviations}

Array CGH: microarray-based comparative genomic hybridization; ASD: autism spectrum disorder; CNV: copy number variant;

DD: developmental delay; EIMFS: epilepsy of infancy with migrating focal seizures; EE: epileptic encephalopathy; ID: intellectual disability; GGE: genetic generalised epilepsy; MLPA: multiplex ligation-dependent probe amplification; NCBI: national center for biotechnology information; NGS: next-generation sequencing; SNP: single nucleotide polymorphism; VUS: variant of uncertain clinical significance.

\section{Competing interests}

The authors declare that they have no competing interests.

\section{Authors' contributions}

MPK, DTP, GK and MJO conceived and designed the project. RT, AEF, CD, DTP and MPK coordinated the project. Participants were recruited and phenotyped by AEF, PB, GJ, HA, EM, AC, CT, SD, FG, JTWN, LH, GT, CW, JN, RHT, DTP and MPK. SKC, MIR and CD facilitated sample archiving. KM, SM, SJ and $\mathrm{HM}$ performed the molecular analysis. ER, $\mathrm{PH}$ and $\mathrm{AEF}$ analysed the data. AEF drafted the manuscript with input from ER, RHT, SM, HM, FG, CW, MIR, MJO, GK, DTP and MPK. All authors read and approved the final manuscript.

\section{Acknowledgements}

The authors would like to thank the patients, families, clinicians and scientists who contributed to this work. This research was funded by the Baily Thomas Charitable Fund and the Medical Research Council (Centre grant G0800509 and Program grant G0801418). The project was also supported by the Wales Epilepsy Research Network and the National Institute for Social Care and Health Research. 


\section{Author details}

'Institute of Medial Genetics, University Hospital of Wales, Cardiff CF14 4XW UK. ${ }^{2}$ Institute of Cancer and Genetics, Cardiff University, Cardiff CF14 4XN, UK. ${ }^{3}$ MRC Centre for Neuropsychiatric Genetics and Genomics, Institute of Psychological Medicine and Clinical Neurosciences, Cardiff University, Cardiff CF24 4HQ, UK. " LIwyneryr Unit, Learning Disability Services, Clasemont Road, Morriston, Swansea SA6 6AH, UK. ${ }^{5}$ Learning Disabilities Directorate, Abertawe Bro Morgannwg University NHS Trust, Treseder Way, Caerau, Cardiff CF5 5WF, UK. ${ }^{6}$ Department of Clinical Genetics, Glan Clwyd Hospital, Betsi Cadwaladr University Health Board, Rhyl, Denbighshire LL18 5UJ, UK. ${ }^{7}$ Department of Paediatric Neurology, University Hospital of Wales, Cardiff CF14 4XW, UK. ${ }^{8}$ Department of Paediatric Neurology, Morriston Hospital, Abertawe Bro Morgannwy University Health Board, Swansea SA6 6NL, UK. 'Department of Paediatrics, Royal Glamorgan Hospital, Cwm Taf University Health Board, Pontyclun, Mid Glamorgan CF72 8XR, UK. ${ }^{10}$ Welsh Epilepsy Centre, Neurosciences Directorate, University Hospital of Wales, Cardiff CF14 4XW, UK. "1Neurology and Molecular Neuroscience Research, Institute of Life Science, College of Medicine, Swansea University, Swansea SA2 8PP, UK.

\section{Received: 20 October 2015 Accepted: 14 April 2016} Published online: 26 April 2016

\section{References}

1. Cooper GM, Coe BP, Girirajan S, Rosenfeld JA, Vu TH, Baker C, et al. A copy number variation morbidity map of developmental delay. Nat Genet. 2011; 43(9):838-46.

2. Pinto D, Pagnamenta AT, Klei L, Anney R, Merico D, Regan R, et al. Functional impact of global rare copy number variation in autism spectrum disorders. Nature. 2010;466(7304):368-72.

3. Mefford HC, Muhle H, Ostertag P, von Spiczak S, Buysse K, Baker C, et al. Genome-wide copy number variation in epilepsy: novel susceptibility loci in idiopathic generalized and focal epilepsies. PLoS Genet. 2010;6(5):e1000962.

4. Rees E, Walters JT, Chambert KD, O'Dushlaine C, Szatkiewicz J, Richards AL, et al. CNV analysis in a large schizophrenia sample implicates deletions at 16p12.1 and SLC1A1 and duplications at 1p36.33 and CGNL1. Hum Mol Genet. 2014;23(6):1669-76.

5. Kalscheuer VM, Tao J, Donnelly A, Hollway G, Schwinger E, Kubart S, et al. Disruption of the serine/threonine kinase 9 gene causes severe X-linked infantile spasms and mental retardation. Am J Hum Genet. 2003;72(6):1401-11.

6. Saitsu H, Kato M, Mizuguchi T, Hamada K, Osaka H, Tohyama J, et al. De novo mutations in the gene encoding STXBP1 (MUNC18-1) cause early infantile epileptic encephalopathy. Nat Genet. 2008;40(6):782-8.

7. Mefford HC, Yendle SC, Hsu C, Cook J, Geraghty E, MCMahon JM, et al. Rare copy number variants are an important cause of epileptic encephalopathies. Ann Neurol. 2011;70(6):974-85.

8. Bartnik M, Szczepanik E, Derwinska K, Wisniowiecka-Kowalnik B, Gambin T, Sykulski M, et al. Application of array comparative genomic hybridization in 102 patients with epilepsy and additional neurodevelopmental disorders. Am J Med Genet B Neuropsychiatr Genet. 2012;159B(7):760-71.

9. Mullen SA, Carvill GL, Bellows S, Bayly MA, Trucks H, Lal D, et al. Copy number variants are frequent in genetic generalized epilepsy with intellectual disability. Neurology. 2013;81(17):1507-14.

10. Striano P, Coppola A, Paravidino R, Malacarne M, Gimelli S, Robbiano A, et al. Clinical significance of rare copy number variations in epilepsy: a case-control survey using microarray-based comparative genomic hybridization. Arch Neurol. 2012;69(3):322-30.

11. Wellcome Trust Case Control Consortium. Genome-wide association study of 14,000 cases of seven common diseases and 3,000 shared controls. Nature. 2007:447(7145):661-78.

12. Wang K, Li M, Hadley D, Liu R, Glessner J, Grant SF, et al. PennCNV: an integrated hidden Markov model designed for high-resolution copy number variation detection in whole-genome SNP genotyping data. Genome Res. 2007;17(11):1665-74.

13. QuickCalcs. GraphPad Software Inc, La Jolla, CA. http://www.graphpad.com/ quickcalcs/. Accessed 25 March 2016.

14. Miller DT, Adam MP, Aradhya S, Biesecker LG, Brothman AR, Carter NP, et al. Consensus statement: chromosomal microarray is a first-tier clinical diagnostic test for individuals with developmental disabilities or congenital anomalies. Am J Hum Genet. 2010;86(5):749-64.

15. Pollard KS, Hubisz MJ, Rosenbloom KR, Siepel A. Detection of nonneutral substitution rates on mammalian phylogenies. Genome Res. 2010;20(1):110-21.
16. Kumar P, Henikoff $\mathrm{S}, \mathrm{Ng} \mathrm{PC}$. Predicting the effects of coding nonsynonymous variants on protein function using the SIFT algorithm. Nat Protoc. 2009;4(7):1073-81. SIFT, http://sift.bii.a-star.edu.sg/.

17. Grantham R. Amino acid difference formula to help explain protein evolution. Science. 1974;185(4154):862-4.

18. Adzhubei IA, Schmidt S, Peshkin L, Ramensky VE, Gerasimova A, Bork P, et al. A method and server for predicting damaging missense mutations. Nat Methods. 2010;7(4):248-9. PolyPhen-2, http://genetics.bwh.harvard.edu/pph2/.

19. Kircher M, Witten DM, Jain P, O'Roak BJ, Cooper GM, Shendure J. A general framework for estimating the relative pathogenicity of human genetic variants. Nat Genet. 2014;46(3):310-5. http://cadd.gs.washington.edu/.

20. Exome Aggregation Consortium (ExAC). Cambridge, MA. http://exac. broadinstitute.org. Accessed 25 March 2016.

21. dbSNP. National Center for Biotechnology Information, Bethesda, MD. http://www.ncbi.nlm.nih.gov/SNP. Accessed 25 March 2016.

22. ClinVar. National Center for Biotechnology Information, Bethesda, MD. http://www.ncbi.nlm.nih.gov/dlinvar. Accessed 25 March 2016.

23. Meng H, Xu HQ, Yu L, Lin GW, He N, Su T, et al. The SCN1A mutation database: updating information and analysis of the relationships among genotype, functional alteration, and phenotype. Hum Mutat. 2015;36(6): 573-80. http://www.gzneurosci.com/scn1adatabase/.

24. NCBI Reference Sequence Database, http://www.ncbi.nlm.nih.gov/refseq/. Accessed 25 March 2016.

25. Kleefstra T, Kramer JM, Neveling K, Willemsen MH, Koemans TS, Vissers LE, et al. Disruption of an EHMT1-associated chromatin-modification module causes intellectual disability. Am J Hum Genet. 2012;91(1):73-82.

26. Talkowski ME, Mullegama SV, Rosenfeld JA, van Bon BW, Shen Y, Repnikova EA, et al. Assessment of 2q23.1 microdeletion syndrome implicates MBD5 as a single causal locus of intellectual disability, epilepsy, and autism spectrum disorder. Am J Hum Genet. 2011;89(4):551-63.

27. Williams SR, Mullegama SV, Rosenfeld JA, Dagli Al, Hatchwell E, Allen WP, et al. Haploinsufficiency of MBD5 associated with a syndrome involving microcephaly, intellectual disabilities, severe speech impairment, and seizures. Eur J Hum Genet. 2010;18(4):436-41.

28. Noh GJ, Graham Jr JM. 2q23.1 microdeletion of the MBD5 gene in a female with seizures, developmental delay and distinct dysmorphic features. Eur J Med Genet. 2012;55(1):59-62.

29. Hodge JC, Mitchell E, Pillalamarri V, Toler TL, Bartel F, Kearney HM, et al. Disruption of MBD5 contributes to a spectrum of psychopathology and neurodevelopmental abnormalities. Mol Psychiatry. 2014;19(3):368-79.

30. Kleefstra T, Brunner HG, Amiel J, Oudakker AR, Nillesen WM, Magee A, et al. Loss-of-function mutations in euchromatin histone methyl transferase 1 (EHMT1) cause the 9q34 subtelomeric deletion syndrome. Am J Hum Genet. 2006;79(2):370-7.

31. Kleefstra T, van Zelst-Stams WA, Nillesen WM, Cormier-Daire V, Houge $\mathrm{G}$, Foulds $\mathrm{N}$, et al. Further clinical and molecular delineation of the $9 \mathrm{q}$ subtelomeric deletion syndrome supports a major contribution of EHMT1 haploinsufficiency to the core phenotype. J Med Genet. 2009; 46(9):598-606.

32. Matthews E, Labrum R, Sweeney MG, Sud R, Haworth A, Chinnery PF, et al. Voltage sensor charge loss accounts for most cases of hypokalemic periodic paralysis. Neurology. 2009;72(18):1544-7.

33. Zangaladze A, Asadi-Pooya AA, Ashkenazi A, Sperling MR. Sporadic hemiplegic migraine and epilepsy associated with CACNA1A gene mutation. Epilepsy Behav. 2010;17(2):293-5.

34. Groen JL, Andrade A, Ritz K, Jalalzadeh H, Haagmans M, Bradley TE, et al. CACNA1B mutation is linked to unique myoclonus-dystonia syndrome. Hum Mol Genet. 2015;24(4):987-93.

35. Chen Y, Lu J, Pan H, Zhang Y, Wu H, Xu K, et al. Association between genetic variation of $\mathrm{CACNA} 1 \mathrm{H}$ and childhood absence epilepsy. Ann Neurol. 2003:54(2):239-43.

36. Heron SE, Khosravani H, Varela D, Bladen C, Williams TC, Newman MR, et al. Extended spectrum of idiopathic generalized epilepsies associated with CACNA1H functional variants. Ann Neurol. 2007;62(6):560-8.

37. Girirajan S, Dennis MY, Baker C, Malig M, Coe BP, Campbell CD, et al, Refinement and discovery of new hotspots of copy-number variation associated with autism spectrum disorder. Am J Hum Genet. 2013;92(2): 221-37.

38. Sebat J, Lakshmi B, Malhotra D, Troge J, Lese-Martin C, Walsh T, et al. Strong association of de novo copy number mutations with autism. Science. 2007; 316(5823):445-9. 
39. Lang B, Pu J, Hunter I, Liu M, Martin-Granados C, Reilly TJ, et al. Recurrent deletions of ULK4 in schizophrenia: a gene crucial for neuritogenesis and neuronal motility. J Cell Sci. 2014;127(Pt 3):630-40.

40. Weiss LA, Shen Y, Korn JM, Arking DE, Miller DT, Fossdal R, et al. Association between microdeletion and microduplication at 16p11.2 and autism. N Engl J Med. 2008;358(7):667-75.

41. Shinawi M, Liu P, Kang SH, Shen J, Belmont JW, Scott DA, et al. Recurrent reciprocal 16p11.2 rearrangements associated with global developmental delay, behavioural problems, dysmorphism, epilepsy, and abnormal head size. J Med Genet. 2010;47(5):332-41.

42. Reinthaler EM, Lal D, Lebon S, Hildebrand MS, Dahl HH, Regan BM, et al. $16 p 11.2600$ kb Duplications confer risk for typical and atypical Rolandic epilepsy. Hum Mol Genet. 2014;23(22):6069-80.

43. Mantegazza M, Gambardella A, Rusconi R, Schiavon E, Annesi F, Cassulini RR, et al. Identification of an Nav1.1 sodium channel (SCN1A) loss-of-function mutation associated with familial simple febrile seizures. Proc Natl Acad Sci U S A. 2005;102(50):18177-82.

44. Claes L, Del-Favero J, Ceulemans B, Lagae L, Van Broeckhoven C, De Jonghe $P$. De novo mutations in the sodium-channel gene SCN1A cause severe myoclonic epilepsy of infancy. Am J Hum Genet. 2001;68(6):1327-32.

45. Escayg A, MacDonald BT, Meisler MH, Baulac S, Huberfeld G, An-Gourfinkel I, et al. Mutations of SCN1A, encoding a neuronal sodium channel, in two families with GEFS + 2. Nat Genet. 2000;24(4):343-5.

46. Harkin LA, MCMahon JM, Iona X, Dibbens L, Pelekanos JT, Zuberi SM, et al. The spectrum of SCN1A-related infantile epileptic encephalopathies. Brain. 2007;130(Pt 3):843-52.

47. Depienne C, Trouillard O, Saint-Martin C, Gourfinkel-An I, Bouteiller D, Carpentier W, et al. Spectrum of SCN1A gene mutations associated with Dravet syndrome: analysis of 333 patients. J Med Genet. 2009;46(3):183-91.

48. Vanoye CG, Gurnett CA, Holland KD, George Jr AL, Kearney JA. Novel SCN3A variants associated with focal epilepsy in children. Neurobiol Dis. 2014;62: $313-22$.

49. Shi X, Yasumoto S, Kurahashi H, Nakagawa E, Fukasawa T, Uchiya S, et al. Clinical spectrum of SCN2A mutations. Brain Dev. 2012;34(7):541-5.

50. Singh NA, Pappas C, Dahle EJ, Claes LR, Pruess TH, De Jonghe $P$, et al. A role of SCN9A in human epilepsies, as a cause of febrile seizures and as a potential modifier of Dravet syndrome. PLoS Genet. 2009;5(9):e1000649.

51. Carranza Rojo D, Hamiwka L, McMahon JM, Dibbens LM, Arsov T, Suls A et al. De novo SCN1A mutations in migrating partial seizures of infancy. Neurology. 2011;77(4):380-3.

52. Lim BC, Hwang H, Kim H, Chae JH, Choi J, Kim KJ, et al. Epilepsy phenotype associated with a chromosome 2q24.3 deletion involving SCN1A: Migrating partial seizures of infancy or atypical Dravet syndrome? Epilepsy Res. 2015; 109:34-9.

53. Suls A, Claeys KG, Goossens D, Harding B, Van Luijk R, Scheers S, et al. Microdeletions involving the SCN1A gene may be common in SCN1Amutation-negative SMEl patients. Hum Mutat. 2006:27(9):914-20.

54. Rudd MK, Keene J, Bunke B, Kaminsky EB, Adam MP, Mulle JG, et al. Segmental duplications mediate novel, clinically relevant chromosome rearrangements. Hum Mol Genet. 2009;18(16):2957-62.

55. Yu HE, Hawash K, Picker J, Stoler J, Urion D, Wu BL, et al. A recurrent 1. $71 \mathrm{Mb}$ genomic imbalance at 2q13 increases the risk of developmental delay and dysmorphism. Clin Genet. 2012;81(3):257-64.

56. Heinzen EL, Radtke RA, Urban TJ, Cavalleri GL, Depondt C, Need AC, et al. Rare deletions at 16p13.11 predispose to a diverse spectrum of sporadic epilepsy syndromes. Am J Hum Genet. 2010;86(5):707-18.

57. Ullmann R, Turner G, Kirchhoff M, Chen W, Tonge B, Rosenberg C, et al. Array CGH identifies reciprocal 16p13.1 duplications and deletions that predispose to autism and/or mental retardation. Hum Mutat. 2007;28(7):674-82.

58. Mefford HC, Cooper GM, Zerr T, Smith JD, Baker C, Shafer N, et al. A method for rapid, targeted CNV genotyping identifies rare variants associated with neurocognitive disease. Genome Res. 2009;19(9):1579-85.

59. Ingason A, Rujescu D, Cichon S, Sigurdsson E, Sigmundsson T, Pietilainen OP, et al. Copy number variations of chromosome 16p13.1 region associated with schizophrenia. Mol Psychiatry. 2011;16(1):17-25.

60. Kirov G, Grozeva D, Norton N, Ivanov D, Mantripragada KK, Holmans P, et al. Support for the involvement of large copy number variants in the pathogenesis of schizophrenia. Hum Mol Genet. 2009;18(8):1497-503.

61. Ramalingam A, Zhou XG, Fiedler SD, Brawner SJ, Joyce JM, Liu HY, et al. $16 p 13.11$ duplication is a risk factor for a wide spectrum of neuropsychiatric disorders. J Hum Genet. 2011;56(7):541-4.
62. Gillentine MA, Schaaf CP. The human clinical phenotypes of altered CHRNA7 copy number. Biochem Pharmacol. 2015;97(4):352-62.

63. Kashevarova AA, Nazarenko LP, Schultz-Pedersen S, Skryabin NA, Salyukova $\mathrm{OA}$, Chechetkina NN, et al. Single gene microdeletions and microduplication of 3p26.3 in three unrelated families: CNTN6 as a new candidate gene for intellectual disability. Mol Cytogenet. 2014;7(1):97.

64. Te Weehi L, Maikoo R, Mc Cormack A, Mazzaschi R, Ashton F, Zhang L, et al. Microduplication of 3p26.3 implicated in cognitive development. Case Rep Genet. 2014;201:295359.

65. van Daalen E, Kemner C, Verbeek NE, van der Zwaag B, Dijkhuizen T, Rump $P$, et al. Social Responsiveness Scale-aided analysis of the clinical impact of copy number variations in autism. Neurogenetics. 2011;12(4):315-23.

66. Catarino CB, Liu JY, Liagkouras I, Gibbons VS, Labrum RW, Ellis R, et al. Dravet syndrome as epileptic encephalopathy: evidence from long-term course and neuropathology. Brain. 2011;134(Pt 10):2982-3010.

\section{Submit your next manuscript to BioMed Central and we will help you at every step:}

- We accept pre-submission inquiries

- Our selector tool helps you to find the most relevant journal

- We provide round the clock customer support

- Convenient online submission

- Thorough peer review

- Inclusion in PubMed and all major indexing services

- Maximum visibility for your research

Submit your manuscript at www.biomedcentral.com/submit
) Biomed Central 